\title{
An Investigation of Anxiety Factors During English Oral Presentation Skills of Engineering Undergraduates in Pakistan
}

\author{
Muhammad Arif Soomro ${ }^{1}$, Insaf Ali Siming ${ }^{1}$, Syed Hyder Raza Shah ${ }^{2}$, Mukhtiar Ali Rajper ${ }^{1}$, Sadia Naz ${ }^{3}$ \& \\ Mansoor Ahmed Channa ${ }^{1}$ \\ ${ }^{1}$ Quaid-e-Awam University of Engineering, Science, and Technology, Nawabshah, Pakistan \\ ${ }^{2}$ Shaheed Benazir Bhutto University, Sanghar Campus, Pakistan \\ ${ }^{3}$ Shaheed Benazir Bhutto University, Shaheed Benzirabad, Pakistan \\ Correspondence: Muhammad Arif Soomro, Department of English, Quaid-e-Awam University of Engineering, \\ Science \& Technology, 67480, Nawabshah, Pakistan. E-mail: muhammadarif@quest.edu.pk
}

Received: March 3, 2019 Accepted: March 30, 2019 Online Published: April 20, 2019

doi:10.5539/ijel.v9n3p203 URL: https://doi.org/10.5539/ijel.v9n3p203

\begin{abstract}
This study aims to investigate the factors affecting oral presentation skills of undergraduate-learners of English that influence their academic performance which potentially can affect professional career. The study has used quantitative instrument as questionnaire partially adopted from McCroskey (1982) for data collection among 100 undergraduate-participants on factors affecting oral communication skills at one Public Sector University. Purposive sampling method was used since participants were selected on specific criteria of only first year engineering undergraduates. The data were analysed through SPSS, v. 20 for obtaining percentage, mean, median, standard deviation, and standard error of mean to be measured. The findings revealed that oral presentation skills as the most problematic for engineering undergraduates. The results also revealed that the several factors affected engineering undergraduates' oral presentations.
\end{abstract}

Keywords: oral presentation, anxiety in English, communication apprehension, engineering, undergraduate

\section{Background of the Study}

This research study is based on factors affecting oral presentation skills of engineering undergraduates learning English at a public sector university. The authors have noticed being teachers in the university that the undergraduates are coping with certain problems when they are asked to deliver oral presentations in classroom. Therefore, the authors decided to investigate such factors that are affecting undergraduates' oral presentation skills. Generally speaking, undergraduates during oral presentations face many problems consequently their academic as well as professional career is affected. Historically speaking, most of the schools and colleges use vernaculars or Sindhi or Urdu as a medium of instruction in their respective provinces of Pakistan and English is taught as a compulsory subject not as a language. When such students are selected in universities for higher studies, they face problems during communication generally more specifically in oral presentations. Based on the personal observation it is found that during English teaching and learning students are directed to cram the rules and reproduce them in examination resultantly, students remain unaware of the vitality of English language for communicative purposes.

It has been noticed the oral presentation skills in English are essential in present day academic career as well as for professional success. Effective communicators know how it is crucial to possess effective communication skills. Graduates require an ever-increasing variety of skills to maintain relevance with global atmosphere of the new millennium (Riemer, 2007) and ever-growing need for good communication skills in English has emerged on high demand around the world (Richards, 2006). 21st century demands the graduates to acquire effective oral presentation skills. Research studies in a recent decade have indicated that $60 \%$ graduates spend their time in communication with people (Trevelayan \& Tilli, 2008). Oral presentation skills in English are essential for undergraduates in this modern means of communication era.

\subsection{Research Objectives}

This paper aims to: 
- Identify the most problematic oral communication skill for engineering undergraduates

- Investigate the factors affecting oral presentation skills of engineering undergraduates learning English

- Provide remedies how to overcome those barriers

\subsection{Research Question}

- Which is the most problematic oral communication skill for undergraduates?

- What factors are involved that are affecting oral presentation skills of engineering undergraduates?

\section{Literature Review}

This paper is conceptualised on Communication Apprehension (CA) theory proposed by McCroskey (1977, p. 78) according him communication apprehension is "an individual's level of fear or anxiety associated with either real or anticipated communication with another person or persons". This theory has remained core of research widely in academia in order to improve oral skills of students (Aly \& Islam, 2005) this is due to its effects on students' academic achievement (McCroskey et al., 1989). Morreale et al. (2000) stated that students' problems are intensified when they respond incorrectly or ineffectively due to poor oral skills. Similarly, in Pakistan undergraduates also face apprehensions during oral presentations, as an assumption communication apprehension prevails among students of Pakistan during studies and this is due to insufficient opportunity of students to interact with others (McCracken \& Barcian, 1991). In another study conducted by Nawab (2012) says that students could be enabled to express themselves freely but mostly they hesitate to communicate in English and cannot go beyond reproducing the notes which they have learnt by heart.

Communication apprehension has been named differently such as reticence and shyness, distress, stage fright, unwillingness to communicate and audience sensitivity (McCroskey, 1982) and it is prevailing among undergraduates of Pakistan as well. This theory of CA was reconceptualised due to consistent research and presently it has been classified into four types of apprehension such as trait-like apprehension, generalised-context apprehension, person-group apprehension and situational apprehension (McCroskey, 1982). Trait-like CA is based on consistent personality-type orientation toward a given mode of communication across a wide variety of contexts such as oral communication, writing, singing (McCroskey, 1982). General-context CA is one step further than trait-like apprehension. It is viewed as relatively similar to trait-like but bearing personality-type orientation toward communication in a given type of context. This CA is based on four types of communication settings public speaking, meetings or classes, dyadic interactions (interviews) and group discussion (McCroskey \& Richmond, 1980) for instance a person can be highly apprehensive in oral presentation but less in group discussion or meetings or interviews. Person-group CA represents the reactions of individuals to communicating with a given person or group of people. The apprehensive response is not because of personality-based but rather it is a reaction to situational hurdles generated by the other person or group for instance when a person communicating with superior, boss or teacher. Situational CA entails individuals' reactions during communicating with an individual or group of audience at a given time. For example, a student may experience little or no apprehension when going to a teacher to ask a question about an assignment, but be afraid if the teacher instruct the student to stay after class to meet with him or her or ask student to explain certain topic or calls a student to see him or her in office due to certain behavior in a class.

High communication apprehensive students talk less (Jordan et al., 2007) and students with high level of apprehension avoid from oral communication interactions and they possess low self-esteem and their academic performance is poor (McCroskey, 1977; Lederman, 1982). Likewise, undergraduates usually avoid taking part in communicative tasks due to communication apprehension they prefer to sit at back seats in classes in order to escape from direct communication with teachers. Thus, CA is directly affecting oral communication performance and it is the most common factor prevailing among of undergraduates. Therefore, this paper aims to explore factor affecting oral presentation skills of undergraduates at Public Sector University.

\section{Research Methodology}

This paper employed quantitative research design in terms of questionnaire survey. Questionnaire was partially adopted from the Personal Report of Communication Apprehension (PRCA-24) constructed by McCroskey (1982) to investigate factors affecting oral communication and oral presentation performance of undergraduates. Respondents were provided close-ended questionnaire that was structured on five likert scale $(1=$ strongly disagree, $2=$ disagree, $3=$ neutral, 4=agree, 5= strongly agree) following McCroskey (1982) for data collection. 


\subsection{Sampling and Questionnaire Designing}

One hundred undergraduates participated in this study. Only 12 female undergraduates were part of the study. All participants aged between 18-23 years. Purposive sampling was employed for data collection because participants were chosen on specific criteria of being in first year of their under graduation. In this perspective, Creswell et al. (2007) emphasized that purposive sampling facilitates researchers to select suitable participants for the study.

The questionnaire consisted of two parts. Part-I asked demographic information and the second part contained 16 statements in total, first statement was categorised into four heading group discussion, meeting/interview, conversation and oral presentation in order to identify which oral communication skill remained the most problematic skill for undergraduates. Ten statements were constructed by the researcher and six statements were directly adopted from McCroskey's PRCA-24 (1982) related to factors affecting oral presentation performance of undergraduates.

\subsection{Respondents and Data Analysis}

All respondents were first year students. These participants belonged to disciplines of civil engineering, mechanical engineering and mathematics and statistics. Data were analysed through SPSS version 20 and results were measured in the percentage, mean, standard error of mean and standard deviations for each variable included in the questionnaire.

\section{Study Findings}

The data obtained from respondents helped to identify oral presentation as the most problematic communication skill among group discussion, meetings or interview, and conversation. The information obtained for this research question was first categorised into four headings of oral communication skills for instance group discussion, meeting/interview, conversation, and oral presentation. First, all four headings were investigated to identify which oral communication skill remained the most problematic for undergraduates. After careful analysis of collected data findings shown in Figure 1, that oral presentation remained the most problematic for undergraduates. The results were categorised in four headings as shown in Figure 1.

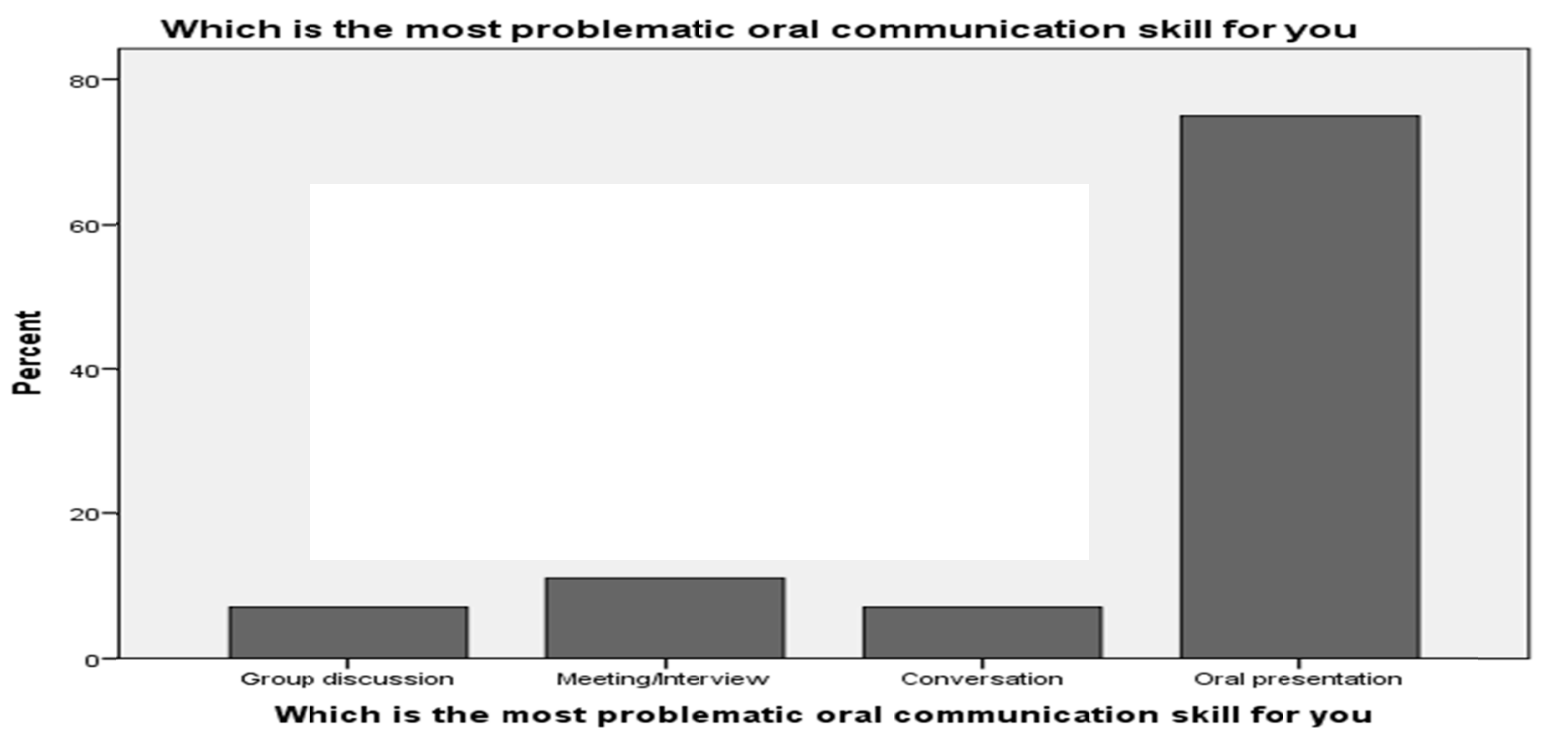

Figure 1. Identification of the most problematic oral communication skill

The results shown in the Figure 1 indicate that $75 \%$ undergraduates found oral presentation skill as the most problematic among rest of oral skills. Seven (7\%) undergraduates responded that group discussion is the problematic, eleven (11\%) responded that during meeting/interview they faced barriers, seven (7\%) undergraduates found conversation as problematic that hindered their academic performance. This indicates that undergraduates' oral presentation skills need consideration at this early stage before entering into professional life. Thus, this finding led further to focus on oral presentation and on factors that are affecting undergraduates' 
oral presentation performance. The results show in Figure 1 that which was the most problematic oral communication skill for undergraduates and the results indicate that $75 \%$ undergraduates responded that they find oral presentation as the most prominent hindrance as compared to other oral communication skills such as group discussion, meeting or interview, or conversation.

Effective oral presentation skills benefit in terms of job promotions, better salary and great appreciation from higher authorities. Thus, findings of this study led further to focus on oral presentation and barriers that hindered oral presentation performance of undergraduates. This is because in future these undergraduates would assist organisations to run business and organisations heavily rely on effective oral communication skills in modern times. Therefore, these undergraduates are required to overcome communication apprehensions and their communication deficiencies in order to be effective communicators. This section consists of the remaining statements 16 relating to barriers that affected oral presentation ability of undergraduates. This section deals with RQ2 and the quantitative results for each statement are presented in the Table 1.

Table 1. Feedback on description of items

\begin{tabular}{|c|c|c|c|c|c|c|c|}
\hline $\begin{array}{l}\text { Item } \\
\text { No. }\end{array}$ & Item & SD* & $\mathrm{D}$ & $\mathrm{N}$ & A & SA & $\mathrm{N}=100$ \\
\hline 1 & I have no fear of giving an oral presentation. & $52 * *$ & 12 & 1 & 12 & 23 & \\
\hline 2 & $\begin{array}{l}\text { Certain parts of my body feel very tense and rigid while giving an oral } \\
\text { presentation. }\end{array}$ & 2 & 6 & 4 & 71 & 17 & \\
\hline 3 & I feel relaxed while giving an oral presentation. & 34 & 51 & 2 & 11 & 1 & \\
\hline 4 & $\begin{array}{l}\text { My thoughts become confused and jumbled when I am giving an oral } \\
\text { presentation. }\end{array}$ & 3 & 2 & 2 & 38 & 55 & \\
\hline 5 & I face the prospect of giving an oral presentation with confidence. & 39 & 45 & 4 & 7 & 5 & \\
\hline 6 & $\begin{array}{l}\text { While giving an oral presentation, I get so nervous I forget facts I really } \\
\text { know. }\end{array}$ & 2 & 9 & 4 & 36 & 49 & \\
\hline 7 & $\begin{array}{l}\text { I am sometimes nervous that the other students in class will laugh at me } \\
\text { when I deliver oral presentation in English. }\end{array}$ & 3 & 9 & 2 & 35 & 51 & \\
\hline 8 & $\begin{array}{l}\text { I usually fail to present my ideas effectively during presentation due to } \\
\text { my stress and nervousness. }\end{array}$ & 2 & 7 & 4 & 39 & 48 & \\
\hline 9 & $\begin{array}{l}\text { I cannot express my ideas effectively due to my poor oral } \\
\text { communication skill. }\end{array}$ & 2 & 7 & 3 & 39 & 48 & \\
\hline 10 & $\begin{array}{l}\text { I avoid answering during my presentation due to my low } \\
\text { self-confidence. }\end{array}$ & 3 & 7 & 1 & 42 & 37 & \\
\hline 11 & $\begin{array}{l}\text { I cannot communicate my thoughts properly due to my low } \\
\text { self-confidence. }\end{array}$ & 1 & 5 & 4 & 33 & 57 & \\
\hline 12 & $\begin{array}{l}\text { I avoid giving presentation in front of my peers due to my low } \\
\text { self-confidence. }\end{array}$ & 1 & 9 & 0 & 37 & 53 & \\
\hline 13 & Shyness is the cause of communication avoidance with others for me. & 2 & 3 & 3 & 40 & 52 & \\
\hline 14 & $\begin{array}{l}\text { Communication teachers do not promote oral presentation activities in } \\
\text { my class. }\end{array}$ & 23 & 39 & 16 & 13 & 9 & \\
\hline 15 & $\begin{array}{l}\text { Due to low motivation from teachers and peer I avoid giving oral } \\
\text { presentation. }\end{array}$ & 2 & 3 & 4 & 28 & 63 & \\
\hline 16 & $\begin{array}{l}\text { I think motivation plays an important role to deliver oral presentation } \\
\text { effectively. }\end{array}$ & 3 & 0 & 4 & 27 & 66 & \\
\hline
\end{tabular}

Note. $* \mathrm{SD}=$ strongly disagree; $\mathrm{D}=$ disagree; $\mathrm{N}=$ neutral; $\mathrm{A}=$ agree; $\mathrm{SA}=$ strongly agree.

**Number in the table shows the responses given by the participants.

On the basis of responses given by the participants, findings of this section were transformed and classified into six emerged headings after using data transformation technique into, fear and anxiety, stress and nervousness, poor oral communication skills, lack of self-confidence, shyness and lack of motivation as most common barriers to oral presentations and role of teachers in promoting oral presentations remained positive. Each finding below is subject to percentage of disagreement, neutrality or agreement of the participants in this study. Thereafter, this study aimed to investigate more in depth about factors that affected oral presentations of undergraduate-learners of English. The findings statistically have been represented in Table 2. The factors affecting oral presentation skill were categorised into six headings for instance, stress and nervousness, lack of motivation, poor oral communication skills, fear \& anxiety, shyness and low of self-confidence according to their percentage order by using descriptive statistics. 
Table 2. Descriptive statistics and ranking of factors affecting oral presentation performance

\begin{tabular}{|c|c|c|c|c|c|}
\hline \multirow{2}{*}{$\begin{array}{l}\text { Factors Affecting Oral Presentation } \\
\text { Performance of Undergraduates }\end{array}$} & \multirow[t]{2}{*}{$\mathrm{N}$} & \multicolumn{4}{|c|}{ Descriptive Statistics } \\
\hline & & Mean & Percent & Std. Error & Std. Deviation \\
\hline Stress and Nervousness & 100 & 3.5000 & $71 \%$ & .07961 & .79614 \\
\hline Lack of Motivation & & 4.4700 & $63 \%$ & .08699 & .86987 \\
\hline Poor Oral Communication Skills & & 4.4000 & $55 \%$ & .08762 & .87617 \\
\hline Fear \& Anxiety & & 4.2200 & $52 \%$ & .10109 & 1.01085 \\
\hline Shyness & & 4.2200 & $51 \%$ & .10596 & 1.05964 \\
\hline Low Self-confidence & & 4.2100 & $51 \%$ & .10180 & 1.01797 \\
\hline
\end{tabular}

The results shown in Table 2 indicate that stress and nervousness is a barrier for $71 \%$ undergraduates that affected oral presentation performance. Usually, due this barrier they forget ideas during oral presentations despite preparation. Additionally, they responded that sometimes peers make fun and laugh at them consequently they become stressed and nervous when appearing before their class fellows. Thus, this problem needs attention of academicians and teachers to guide and assist undergraduates to overcome this barrier because they would in future become part of multinational organisations. Furthermore, mean score about stress and nervousness is 3.50 while st. deviation is .79 with .07 st. error of mean that clearly shows that most of undergraduates were stressed and nervous during oral presentations.

On lack of motivation $63 \%$ undergraduates agreed as the second most frequent factor affecting oral presentation performance. Undergraduates stated that due to low motivation from both teacher and peers they avoid giving oral presentations. Interestingly, they indicated that teachers hardly promote presentation activities. Hence, lack of motivation has emerged as second most prominent barrier for them that impeded their way to become effective oral presenters. Besides, mean score about lack of motivation is 4.47 while st. deviation is .08 with .86 st. error of mean which reveals that undergraduates found lack of motivation as a barrier affecting their oral presentations. Table 2 indicates that $55 \%$ undergraduates agreed that due to poor oral communication they could not express their thoughts effectively. Consequently, they cannot achieve better grades during academic career. Hence, they should be provided more opportunities to overcome this barrier. In addition, mean score about poor oral communication skills is 4.40 while st. deviation is .87 and st. error of mean is .87 which reveals that they are coping with poor oral communication skills as a barrier while oral presentations.

In Table 2, 52\% percent of undergraduates agreed on fear and anxiety as barrier affecting their oral presentation performance. Additionally, undergraduates due to this barrier cannot communicate their ideas effectively and they remain silent or sometimes mumble during oral presentations. In addition, they feel worried and do not feel relaxed therefore, they try to finish their oral presentation as soon as possible. Besides, results drawn indicated that the mean score about fear $\&$ anxiety is 4.22 while st. deviation is 1.01 and st. error of mean is .10 which means undergraduates had fear \& anxiety. The results in Table 1 indicate that $51 \%$ percent of undergraduates agreed on shyness as a barrier affecting their oral presentation performance. Furthermore, they stated that due to unfamiliarity with audience they shy and hesitate to communicate their opinions during oral presentations. However, they possessed knowledge but mostly failed to share due to shyness. Shyness is quoted as the most common barrier to oral communication (McCroskey, 1986; Khan \& Ali, 2009). However, mean score about shyness is 4.22 while st. deviation is 1.05 and st. error of mean is .10 that tells shyness is a barrier to communication for them during oral presentations.

Low self-confidence is last barrier on that $51 \%$ undergraduates found it as a factor affecting their oral presentation performance. Interestingly, they agreed due to this barrier their certain body parts feel very tense and sometimes become rigid. They do not confidently face oral presentation chances rather avoid them. Moreover, their thoughts become jumbled and disordered and they avoid giving oral presentations before peers. Their response shows that they also avoid answering during oral presentations due to low self-confidence. Moreover, mean score about low self-confidence is 4.21 while st. deviation is 1.01 with .10 st. error of mean. This means undergraduates' performance is affected due to low self-confidence during oral presentations.

\section{Discussion}

The results for oral presentation barriers of undergraduates were found stress and nervousness, lack of motivation, poor oral communication skills, fear and anxiety, shyness and low self-confidence. These barriers hindered undergraduates' oral presentation performances.

Stress and nervousness is identified as a barrier for undergraduates that hindered their oral presentations. Usually, due to this barrier they forget ideas during oral presentations although they come prepared. Additionally, they 
responded that sometimes peers make fun and laugh at them consequently they become stressed and nervous when appearing before their class fellows. Students feel stressed and nervous during presentation (Lucas, 2001; Kakepoto et al., 2012). Thus, this problem needs attention of academicians and teachers to guide and assist undergraduates to overcome this barrier because they would in future become part of multinational organisations. The results however, revealed that 'stress and nervousness' was a barrier that created problems for undergraduates during oral presentations.

Lack of motivation is the second most common barrier for undergraduates during oral presentations that hindered their performances. Undergraduates face lack of motivation from both side teachers and peers because teachers hardly promote presentation activities. Most of learners are not encouraged to learn certain subjects such as oral presentations (Riemer, 2002; Kakepoto et al., 2012). Thus, it is suggested that undergraduates should be provided ample opportunities that focus on oral presentations to prepare them productive undergraduates for future life.

Poor oral communication skills remained another barrier for undergraduates and due to this barrier they cannot express their opinions during oral presentations. Consequently, they cannot achieve better grades during academic career. If this problem of poor oral communication skills prevailed it will affect their professional life and students often fail to get jobs due to this problem (Cangeslosi et al. 1998). The main reasons behind poor oral communication skills are inadequate oral presentation opportunities and consistent teacher-centered classes. Students possessed poor oral communication skills for oral presentation and it was barrier for them (Kakepoto et al., 2012).

Fear and anxiety is a barrier to oral presentations for undergraduates due to which they cannot communicate their ideas effectively and they remain silent or sometimes they mumble during oral presentations. Additionally, they seem worried and do not feel relaxed therefore, they try to finish their oral presentation as soon as possible. They also agreed that their body parts start shivering and more often their legs shiver during oral presentations. Thus, fear and anxiety is barrier for undergraduates to their oral presentation performances.

Shyness also is a barrier for undergraduates. Respondents stated that due to unfamiliarity with audience they shy and hesitate to communicate their opinions during oral presentations. However, they possessed knowledge but mostly failed to share due to shyness. Shyness is quoted as the most common barrier to oral communication (McCroskey, 1986; Khan \& Ali, 2009).

Low self-confidence is also identified as a barrier for undergraduates and they agreed that due to this barrier their certain body parts feel very tense and become rigid. They do not confidently face oral presentation chances rather avoid them. Moreover, their thoughts become jumbled and disordered and they avoid giving oral presentations before peers. Their feedback shows that they also avoid answering during oral presentations due to low self-confidence. Low self-confidence can hamper graduates to be hired and they need to practice oral presentations to overcome this barrier (Kakepoto et al., 2012). Thus, undergraduates should be provided more opportunities to overcome oral presentation barriers.

\section{Significance of the Study}

This paper's findings would facilitate communication instructors in Pakistan to resolve barriers that are affecting oral communication and oral presentation performance of undergraduates during academic career. Furthermore, both undergraduates and instructors would get familiar with barriers, consequently; communication teachers or instructors would be able take effective measures to eradicate these barriers.

\section{Limitations of the Study}

This paper was limited to be noted. First, it focused on oral presentations but the study could be expanded to explore more in-depth barriers affecting other oral communication skills. Second, only one public sector university was selected consequently the findings cannot be generalized and time restriction was limited. Due to short span of time this research study was not extended and could not collect data from various institutions such as private. Lastly, undergraduates possessed rural and urban background and data were collected without distinction of backgrounds. However, this study would be helpful in future studies with respect to the specific area of research.

\section{Conclusion with Suggestions}

Based on the findings, this paper revealed that undergraduates' oral communication skills performance was affected in general but more particularly during oral presentations. The major factors that affected their oral presentation performance were identified as fear and anxiety, stress, tension and nervousness, low self-confidence, shyness, poor communication skills and lack of motivation. These barriers prevail among them 
because of communication apprehension. Thus, there are suggestions given below to overcome these oral presentation barriers of undergraduates in order enhance their academic performance as well as to prepare them for workplace. Therefore, following are the main suggestion to develop effective oral presentation of first year students and professionals.

- $\quad$ Provide enough practice: The communication teachers should provide undergraduates ample opportunities for the development of effective oral communication skills.

- Motivate the undergraduates: Motivation plays paramount role to achieve goals therefore, teachers should motivate undergraduates to participate in oral presentations.

- Need for Trainings: Training for undergraduates during study times could help them to overcome identified barriers during oral presentations.

- Create awareness among undergraduates: They should be explained the importance and knowledge of oral communication skills particularly oral presentation.

\section{References}

Aly, I., \& Islam, M. (2005). Factors affecting oral communication apprehension among business students: Ana empirical study. The Journal of American Academy of Business, Cambridge, 2, 98-103.

Baum, E. (2000). Engineering accreditation in the United States of America-Criteria 2000. Proc. 2nd Global Congress on Engng. Educ., Wismar, Germany.

Cangelosi, B. R., \& Peterson, M. L. (1998). Peer teaching assertive communication strategies for the workplace. ERIC Document Reproduction Service No. ED427166.

Creswell, J. W., \& Plano Clark, V. L. (2007). Designing and conducting mixed methods approaches. Thousand Oaks. CA: Sage Publications.

Hynes, G. E., \& Bhatia, V. (1996). Graduate business students' preferences for the managerial communication course curriculum. Business Communication Quarterly, 59(2), 45-55. https://doi.org/10.1177/108056999605900204

Jordan, W. J., \& Powers, W. G. (2007). Development of a measure of student apprehension toward communicating with instructors. Human Communication, A Publication of the Pacific and Asian Communication Association, 10(1), 20-30.

Kakepoto, I., Habil, H., Omar N. A. M., \& Said, H. (2012). New Trends in Modern Industry and Oral Presentation Barriers of Engineers of Pakistan. Research on Humanities and Social Sciences, 2(9), 176181.

Khan, N., \& Ali, A. (2009). Improving the speaking ability in English: The students' perspective. Precedia Social and Behavioral Sciences, 2, 3575-3579. https://doi.org/10.1016/j.sbspro.2010.03.554

Lederman, L. C. (1982). Suffering in silence: The effects of fear of talking on small group participation. Group \& Organizational Studies, 7, 279-294.

Lucas, S. E. (2001). The art of public speaking (7th ed.). Boston, MA, McGraw-Hill.

McCroskey, J. C. (1977). Oral communication apprehension: A summary of recent theory and research. Human Communication Research, 4, 78-96. https://doi.org/10.1111/j.1468-2958.1977.tb00599.x

McCroskey, J. C. (1982). An introduction to rhetorical communication (4th ed.). Englewood Cliffs, NJ: Prentice-Hall.

McCroskey, J. C. (1982a). Oral Communication Apprehension: A Reconceptualization. Communication Yearbook, 6. Beverly Hills: SAGE Publications.

McCroskey, J. C., Booth-Butterfield, S., \& Payne, S. K. (1989). The impact of communication on college student retention and success. Communication Quarterly, 26, 82-111. https://doi.org/10.1080/01463378909385531

McCracken, J. D., \& Barcian, J. D. T. (1991). Difference between Rural and Urban Schools, students' Characteristics, and Students Aspirations in Ohio. Journal of Research in Rural Education, 7(2), 29-40.

McPherson, B. (1998). Student Perceptions about Business Communication in their Careers. Business Quarterly, 6(21), 68-79. https://doi.org/10.1177/108056999806100209 
Morreale, S. P., Osborn, Mi. M., \& Pearson, J. C. (2000). Why Communication is Important: A Rationale for the Centrality of the Study of Communication. Journal of the Association for Communication Administration, 29, 1-25. https://doi.org/10.1080/03634520701861713

Nawab, A. (2012). Is it the way to teach language the way we teach language? English language teaching in rural Pakistan. Academic Research International, 2(2), 696-705.

Richards, J. C. (2006). Communicative Language Teaching Today. New York: Cambridge University Press.

Riemer, M. J. (2007). Communication Skills for the 21st Century Engineer. Global Journal of Education, 11(1).

Trevelyan, J., \& Tilli, S. (2008). Longitudinal Study of Australian Engineering Graduates: Preliminary Results. Society for Engineering Education (ASEE) Annual Conference, Pittsburgh.

\section{Copyrights}

Copyright for this article is retained by the author, with first publication rights granted to the journal.

This is an open-access article distributed under the terms and conditions of the Creative Commons Attribution license (http://creativecommons.org/licenses/by/4.0/). 